\title{
Perancangan Ulang Tata Letak Gudang Menggunakan Metode Konvensional, Corelap Dan Simulasi Promodel
}

\author{
W. I. Rahmadani
}

\begin{abstract}
Abstrak - Tujuan dari penelitian ini adalah untuk menentukan desain perancangan tata letak usulan agar penempatan peralatan dan mesin tepat sehingga gudang terlihat rapi serta pemanfaatan area kosong lokasi gudang agar penataan area gudang menjadi optimal. Pada PT. PM, gudang digunakan sebagai tempat penyimpanan dan perbaikan peralatan dan mesin, yang sewaktu-waktu akan digunakan sesuai dengan kebutuhan perusahaan. Tetapi ada beberapa peralatan dan mesin yang ditempatkan tidak sesuai dengan penataan. Akibatnya membuat area didalam gudang menjadi terlihat berantakan dan sempit. Kemudian juga ada dibeberapa area yang kurang maksimal pemanfaatannya. Perhitungan yang dilakukan menggunakan metode konvensianal, melakukan perhitungan activity relationship chart (ARC), activity relationship diagram (ARD), area allocation diagram (AAD) dan pembuatan layout tata letak gudang yang baru serta menggunakan corelap dan Promodel. Tata letak usulan menunjukan beberapa perubahan diantaranya jarak antara pipa besi dengan keranjang besi yang yang sebelumnya berjarak 53 meter, pada tata letak usulan berjarak hanya 1 meter. Jarak antara 4 container yang sebelumnya memiliki jarak 10 meter, pada tata letak usulan hanya berjarak 1 meter. Penataan lokasi warehouse menjadi lebih rapih berdasarkan hubungan kedekatan, area kosong sudah berkurang dan peralatan menjadi lebih dekat penempatannya dengan rata-rata kedekatan jaraknya 1 meter. Dengan hasil tersebut diharapkan penataan lokasi warehouse menjadi lebih baik lagi.
\end{abstract}

Kata Kunci- Tata Letak, Metode Konvensional, Corelap, Promodel

\begin{abstract}
The pupose of this research is to determine the design oh the proposed layout so that the placement of equitment and machinery is right so that the warehouse looks neat and the utilization of the empty area of the warehouse so that the warehouse area arrangement becomes optimal.At PT. PM, the warehouse is used as a place to store and repair equipment and machinery, which at any time will be used in accordance with the needs oh the company. But there are some equipment and machines placed that are not in accordance with the arrangement. As a result, make the area in the warehouse look messy and narrow. Then there are also some areas that are not maximally utilized. Calculations carried out using conventional methods, calculating relationship chart activities (ARC), activity relationship diagrams (ARD), area allocation diagrams $(A A D)$ and creating new warehouse layout layouts and using Corelap and Promodel. The layout of the proposal shows several changes including the distance between the iron pipe and the iron basket which was previously 53 meters away, in the proposed layout, only 1 meter away. The distance between 4 containers that previously had a distance of 10 meters, in the proposed layout is only 1 meter away. The arrangement of the warehouse location is more neat based on the proximity relationship, the empty area has been reduced and the equipment is closer to its placement with an average proximity of 1 meter. With these results it is expected that the arrangement of the warehouse location will be even better.
\end{abstract}

Keywords - Layout, Conventional Method, Corelap, Promodel

\section{PENDAHULUAN}

$\mathrm{P}$ erkembangan dunia industri yang semakin maju serta persaingan antar perusahaan yang semakin ketat, maka perusahaan dituntut untuk semakin memaksimalkan hasil kerja dari karyawan dan fasilitas pendukung perusahaan. Salah satu fasilitas pendukung perusahaan adalah gudang, gudang memiliki peran yang sangat penting untuk perusahaan Karena gudang berfungsi sebagai tempat penyimpanan barang dan peralatan yang dimiliki perusahaan. Gudang juga bermanfaat untuk menyimpan peralatan dan mesin agar tetap baik digunakan saat waktunya dibutuhkan.

Perancangan tata letak dan penempatan mesin yang tepat sangat dibutuhkan oleh perusahaan, karena apabila perusahaan tidak memperhitungkan perancangan dengan baik maka akan berpengaruh terhadap kegiatan yang dilakukan oleh perusahaan itu sendiri. Perancangan tersebut diantaranya adalah perancangan luas area gudang dan fasilitas yang ada didalamnya, jumlah mesin yang dibutuhkan oleh perusahaan sesuai dengan kebutuhan perusahaan.

Antrian adalah suatu garis tunggu dari nasabah (satuan) yang memerlukan layanan dari satu atau lebih pelayan (fasilitas pelayanan). Salah satu hal yang kurang efektif dan efisien didalam system antrian yaitu panjangnya antrian dikarenakan kurangnya jumlah loket yang beroperasi. Melihat setiap orang memiliki kepentingan masing-masing untuk segera menyelesaikan pekerjaan ketimbang menunggu lama dalam suatu antrian [5].

Penelitian perancangan ulang tata letak atau membuat usulan tata letak baru sudah banyak dilakukan oleh para peneliti, salah satunya adalah 
penelitian yang berjudul "Usulan Rancangan Tata Letak Fasilitas Dengan Menggunakan Metode Computerized Relationship Layout Planning (Corelap) Di Perusahaan Konveksi”. Dengan tujuan perbaikan, yaitu menata ulang tata letak fasilitas yang sudah ada atau membuat rancangan tata letak yang baru. Rancangan tata letak yang sesuai agar dapat membantu perusahaan dalam kegiatan produksinya [3].

Penelitian ini dimaksudkan untuk menentukan desain perancangan tata letak usulan agar penempatan peralatan dan mesin tepat sehingga megakibatkan gudang terlihat rapi serta pemanfaatan area kosong lokasi gudang agar penataan area gudang menjadi maksimal.

\section{METODE PENELITIAN}

Penelitian dilakukan langsung di PT. PM yang mengamati mengenai perancangan tata letak warehouse dan penerapannya didalam aktifitasaktifitas warehouse sehari-hari. Sehingga penulis dapat mengamati secara langsung masalah yang terjadi pada tata letak warehouse saat itu.

Penelitian ini menggunakan metode konvensional dengan menentukan secara manual derajat kedekatan sampai membuat layout usulan, kedua menggunakan metode Corelap, ketiga menggunakan software Promodel. Dari kedua metode yang digunakan (metode konvensional dan corelap) kemudian dibandingkan agar didapatkan hasil yang paling optimal.

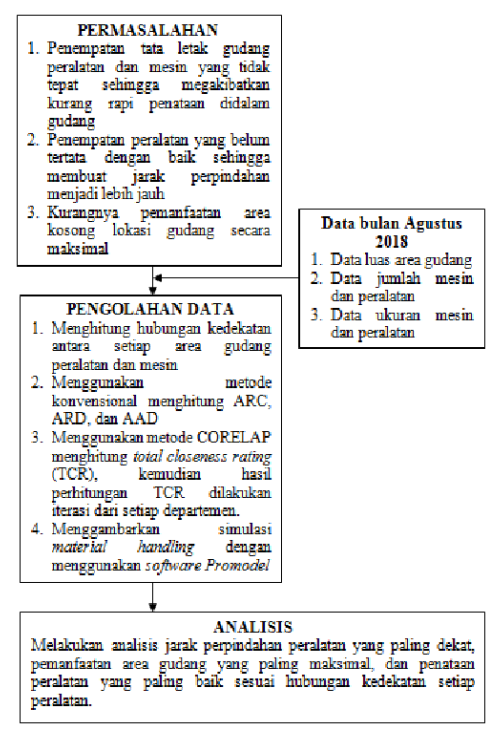

Gambar 1. Kerangka Berpikir

Fasilitas adalah suatu yang dibangun atau diinvestasikan ditujukan untuk melayani atau melaksanakan suatu aktivitas. Perancangan fasilitas merupakan rancangan dari fasilitas-fasilitas industri yang akan dibangun atau didirikan. Tujuannya adalah untuk menempatkan fasilitas-fasilitas/ pabrik yang cocok/sesuai ditinjau dari segi biaya maupun keuntungan (diupayakan terjadi optimalisasi dari beberapa segi, antara lain: tenaga kerja, bahan baku, pasar dan lain-lain) [1].

Tata letak yang baik memenuhi syarat-syarat diatas akan memiliki keuntungan lebih, antara lain [2]:

1. waktu dan biaya proses keseluruhan akan diperkecil dengan mengurangi penanganan dan pemindahan yang tidak perlu, dan secara umum meningkatkan efektivitas seluruh pekerjaan.

2. Supervisi dan pengendalian produksi akan disederhanakan dengan pengurangan 'sudut-sudut tersembunyi' dimana informasi atau bahan dapat tersesat.

3. Perubahan-perubahan program akan dapat ditampung dengan tepat.

4. Keluaran total dari pabrik dimaksud akan menjadi setinggi mungkin dengan menggunakan ruangan yang tersedia seefektif mungkin.

5. Perasaan bersatu diantara karyawan akan digalakkan dengan menghindari pemisahan yang tak perlu.

Algoritma CORELAP menggunakan peringkat hubungan kedekatan yang dinyatakan dalam Total Closeness Rating (TCR) dalam pemilihan penempatan stasiun kerja. Algoritma ini merupakan algoritma pembangunan (construction algorithm), yaitu suatu algoritma yang digunakan untuk menghasilkan rancangan layout baru yang tidak bergantung atau tidak memerlukan initial layout. Berdasarkan Total Closeness Rating (TCR) untuk setiap departemen, di mana TCR adalah jumlah annilainumeris yang dihitung berdasarkan rating hubungan keterdekatan secara sistematis. Jika suatu departemen sudah dipilih, penempatan departemen dapat berdasarkan Placing Rating dengan melihat nilai weight closeness rating atau jumlah bobot antar departemen yang sudah masuk dengan yang akan masuk. Placing rating merupakan panjang batas dibandingkan dengan panjang batas dan jumlah unit persegi yang bersisian dengan yang berdekatan. Untuk evaluasi tata letak dapat menggunakan layout score yaitu jumlah closeness rating numeric dikalikan 
dengan panjang lintasaan terpendek untuk semua departemen [3].

Promodel adalah sebuah softwares imulasi berbasis windows yang digunakan untuk mensimulasikan dan menganalisis suatu. Promodel memberikan kombinasi yang baik dalam pemakaian, fleksibilitas, dan memodelkan suatu system nyata agar tampak lebih realistik. Dalam promodel, selama simulasi berlangsung dapat diamati animasi dari kegiatan yang sedang berlangsung dan hasilnya akan ditampilkan dalam bentuk table mau pun grafik yang memudahkan untuk penganalisaan. Untuk membangun model suatu sistem yang diinginkan, promodel menyediakan beberapa elemen-elemen yang tepat disesuakan untuk membuat model system produksi. Beberapa elemen-elemen dasar yang ada seperti location, entities, processing, arrival, resources, path network dan menjalankan simulasi [4].

\section{Tata letak awal warehose}

\section{HASIL DAN PEMBAHASAN}

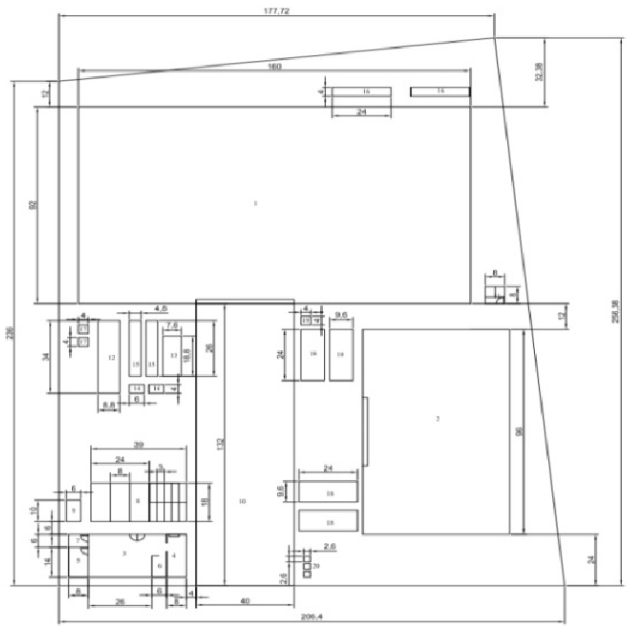

Gambar2.Tata letak warehouse

Gambar diatas merupakan gambar tata letak awal dari PT. PM yang diambil sebagai bahan untuk penelitian ini. Dengan ukuran area dan peralatan yang ada pada warehouse yang tertera pada Tabel 1 .

1. Metode konvensional

\section{a. Activity Relationship Chart (ARC)}

Pada perhitungan ARC mendapatkan hubungan kedekatan dari setiap departemen pada warehouse sesuai dengan alasan yang digunakan.
e-ISSN 2657-0181

Data ukuran luas area area ruang dan peralatan

Tabel 1. data ukuran luas area ruang dan peralatan

\begin{tabular}{|c|c|c|c|}
\hline No & Nama & Ukuran & Jumlah \\
\hline 1 & Luas warehouse besar & $40 \mathrm{~m} \times 23 \mathrm{~m}$ & 1 \\
\hline 2 & Warehouse kecil & $24 \mathrm{~m} \times 15 \mathrm{~m}$ & 1 \\
\hline 3 & Office & $6 \mathrm{~m} \times 5 \mathrm{~m}$ & 1 \\
\hline 4 & Security & $5 \mathrm{~m} \mathrm{x} 2 \mathrm{~m}$ & 1 \\
\hline 5 & Mushola and wudhu & $3,5 \mathrm{~m} \times 2 \mathrm{~m}$ & 1 \\
\hline 6 & Pantry & $2 \mathrm{~m} \times 1,5 \mathrm{~m}$ & 1 \\
\hline 7 & Toilet & $2 \mathrm{~m} \times 1 \mathrm{~m}$ & 1 \\
\hline 8 & Parkiran mobil dan motor & $10 \mathrm{~m} \times 3 \mathrm{~m}$ & 1 \\
\hline 9 & Smoking area & $2,5 \mathrm{~m} \times 1,5 \mathrm{~m}$ & 1 \\
\hline 10 & Jalan utama & $33 \mathrm{~m} \times 10 \mathrm{~m}$ & 1 \\
\hline 11 & Toilet 2 & $2 \mathrm{~m} \times 2 \mathrm{~m}$ & 1 \\
\hline 12 & Kapal & $8,5 \mathrm{~mm} \times 2,2 \mathrm{~m}$ & 1 \\
\hline 13 & Perahu karet & $4,7 \mathrm{~m} \mathrm{x} 1,9 \mathrm{~m}$ & 1 \\
\hline 14 & Keranjang besi & $6,5 \mathrm{~m} \times 1,2 \mathrm{~m}$ & 1 \\
\hline 15 & Lars & $1,5 \mathrm{~m} \times 1 \mathrm{~m}$ & 2 \\
\hline 16 & Pipa besi $6 \mathrm{~m} 5 \mathrm{~m} 4 \mathrm{~m} 2 \mathrm{~m}$ d: $6 \mathrm{~cm}$ & $6 \mathrm{~m} \times 1 \mathrm{~m}$ & $200 / 2 \mathrm{rak}$ \\
\hline 17 & Water tank & $1 \mathrm{~m} \times 1 \mathrm{~m}$ & 2 \\
\hline 18 & Tempat sampah & $0,65 \mathrm{~m} \times 0,65 \mathrm{~m}$ & 3 \\
\hline 19 & Container & $2,4 \mathrm{~m} \times 6 \mathrm{~m}$ & 4 \\
\hline 20 & Water tank and spraying machine & $1 \mathrm{~m} \times 1 \mathrm{~m}$ & 1 \\
\hline
\end{tabular}

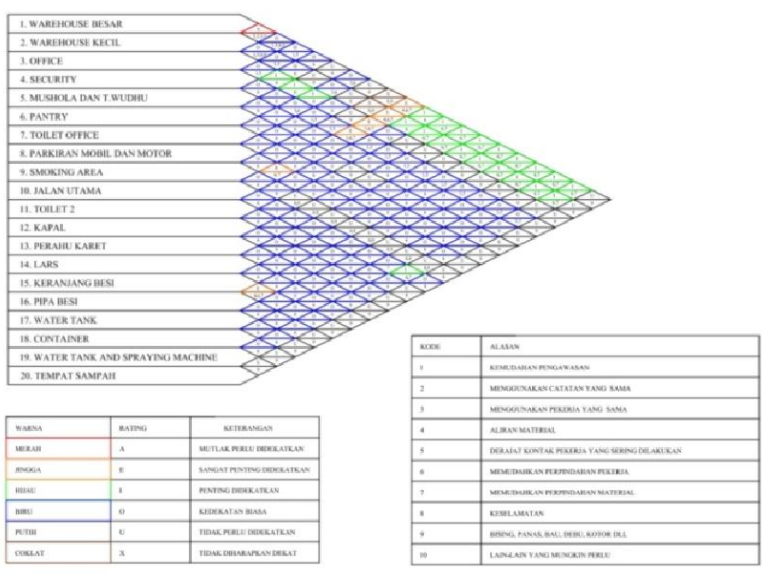

Gambar 3. Activity Relationship Chart dan keterangan

b. Activity Relationship Diagram (ARD)

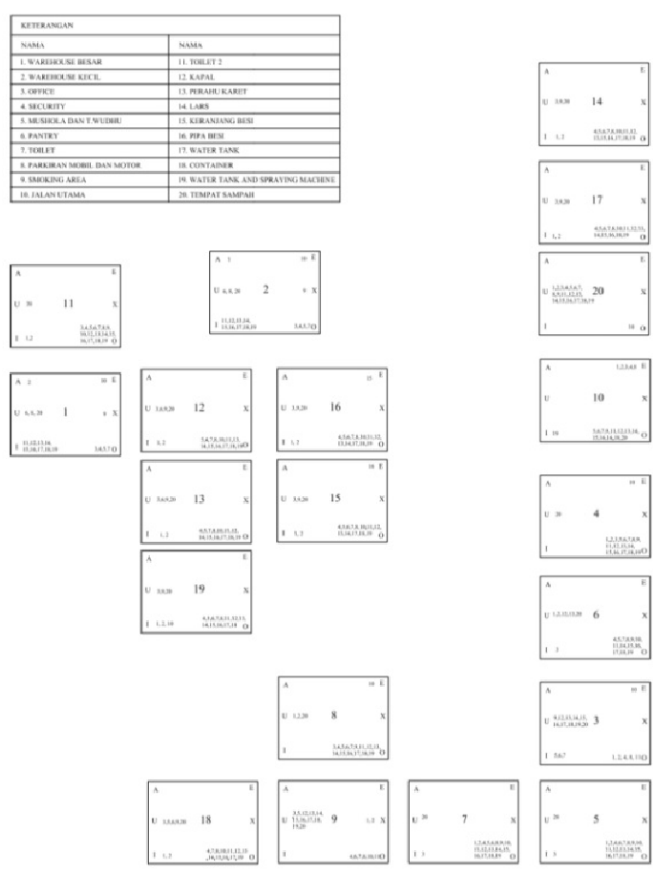

Gambar 4. Activity Relationship Diagram 
Pada perhitungan ARD didapatkan gambaran posisi kedekatan dari setiap departemen berdasarkan hasil dari hubungan kedekatan pada perhitungan ARC. Lokasi disusun berdasarkan kedekatan antar departemennya.

\section{c. Area Alocation Diagram (AAD)}
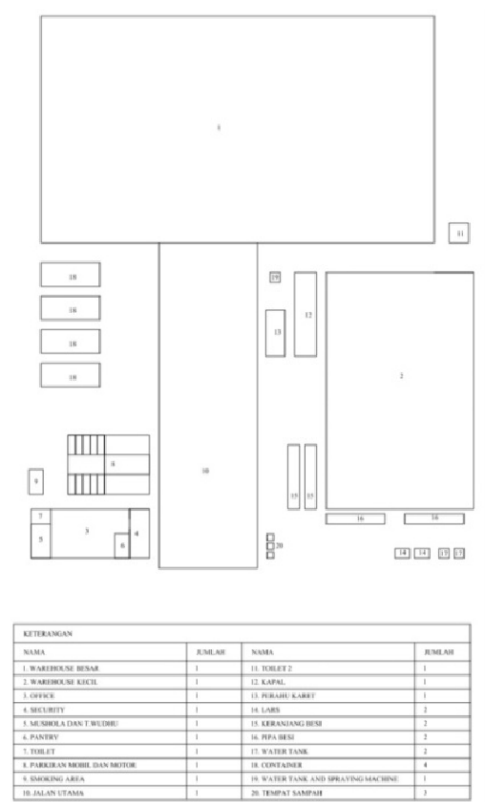

Gambar 5. Area Alocation Diagram dan keterangan

Pada perhitungan AAD dihasilkan gambaran tata letak berdasarkan hasil dari perhitungan ARD yang digambarkan sesuai dengan ukuran tata letak awal.

\section{d. Template}

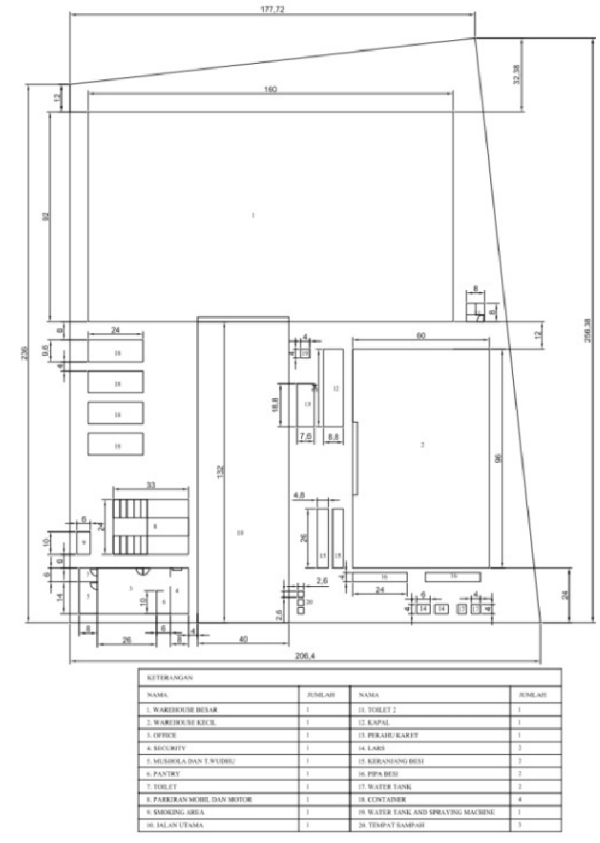

Gambar 6. Template
Pada Tamplatedihasilkan gambaran dari semua perhitungan dengan disertai penjelasan berupa ukuran luas departemennya. Menghasilkan jarak antar departemen 2 meter dan jarak ke jalan utama antara 1 meter sampai 10 meter. area kosong yang tersisa seluas 250 meter.

2. Metode Corelap

a. Activity Relationship Chart (ARC)

Pada perhitungan ARC mendapatkan hubungan kedekatan dari setiap departemen pada warehouse sesuai dengan alasan yang digunakan.

b. Perhitungan TCR

Perhitungan TCR (Total Closeness Rating) berdasarkan data kualitatif ARC pada gambar 4.6, yang dikonversikan dalam angka, yaitu $\mathrm{A}=5, \mathrm{E}=4, \mathrm{I}=3, \mathrm{O}=2, \mathrm{U}=1, \mathrm{X}=0$. Cara mendapatkan nilai TCR adalah dengan memperhatikan hubungan antara Departemen yang satu dengan departemen-departemen yang lain yang dapat dilihat pada ARC.

Departemen A:
$\mathrm{A}-\mathrm{B}=\mathrm{A}=5$
$\mathrm{A}-\mathrm{L}=\mathrm{I}=3$
$\mathrm{A}-\mathrm{C}=\mathrm{O}=2$
$\mathrm{A}-\mathrm{M}=\mathrm{I}=3$
$\mathrm{A}-\mathrm{D}=\mathrm{O}=2$
$\mathrm{A}-\mathrm{N}=\mathrm{I}=3$
$\mathrm{A}-\mathrm{E}=\mathrm{O}=2$
$\mathrm{A}-\mathrm{O}=\mathrm{I}=3$
$\mathrm{A}-\mathrm{F}=\mathrm{U}=1$
$\mathrm{A}-\mathrm{P}=\mathrm{I}=3$
$\mathrm{A}-\mathrm{G}=\mathrm{O}=2$
$\mathrm{A}-\mathrm{Q}=\mathrm{I}=3$
$\mathrm{A}-\mathrm{H}=\mathrm{U}=1$
$\mathrm{A}-\mathrm{R}=\mathrm{I}=3$
A-I $=X=0$
A-S $=\mathrm{I}=3$
$\mathrm{A}-\mathrm{J}=\mathrm{E}=4$
$\mathrm{A}-\mathrm{T}=\mathrm{U}=1$
$\mathrm{A}-\mathrm{K}=\mathrm{I}=3$

Tabel 2. Hasil TCR

\begin{tabular}{ccc}
\hline Departemen & TCR & Urutan \\
\hline A & 47 & 2 \\
B & 47 & 3 \\
C & 33 & 18 \\
D & 38 & 7 \\
E & 38 & 8 \\
F & 34 & 17 \\
G & 38 & 9 \\
H & 37 & 11 \\
I & 24 & 19 \\
J & 49 & 1 \\
K & 39 & 4 \\
L & 36 & 15 \\
M & 36 & 16 \\
N & 37 & 12 \\
O & 39 & 5 \\
P & 39 & 6 \\
Q & 37 & 13 \\
R & 37 & 14 \\
S & 38 & 10 \\
T & 20 & 20 \\
\hline
\end{tabular}


Tabel diatas berisikan data dari semua hasil perhitungan TCR dari semua departemen yang ada.

\section{c. Iterasi Corelap}

Iterasi 1

Departemen J sebagai pusat sebagai pusat. Departemen yang diletakan selanjutnya adalah departemen yang memiliki hubungan terdekat dengan departemen J, yaitu departemen A besar memiliki hubungan $\mathrm{E}$ dengan departemen J.

\begin{tabular}{|l|l|l|}
\hline 8 & 7 & 6 \\
\hline 1 & $\mathrm{~J}$ & 5 \\
\hline 2 & 3 & 4 \\
\hline
\end{tabular}

Jika departemen A alokasikan di:

Lokasi 1, 3, 5, 7 bernilai : 4

Lokasi 2, 4, 6, 8 bernilai : $0,5 \times 4: 2$

Maka departemen A ditempatkan dilokasi nomor 1 karena memiliki nilai yang paling besar.

d. Hasil perhitungan

\begin{tabular}{|c|c|c|c|c|c|}
\hline $\mathrm{C}$ & $Q$ & $\mathrm{~N}$ & $\mathrm{H}$ & $\mathrm{M}$ & \\
\hline $\mathrm{F}$ & $P$ & A & $\mathrm{J}$ & D & \\
\hline \multirow[t]{2}{*}{$\mathrm{T}$} & $\mathrm{O}$ & B & $\mathrm{K}$ & $\mathrm{E}$ & I \\
\hline & $\mathrm{S}$ & $\mathrm{G}$ & $\mathrm{R}$ & $\mathrm{L}$ & \\
\hline
\end{tabular}

e. Template

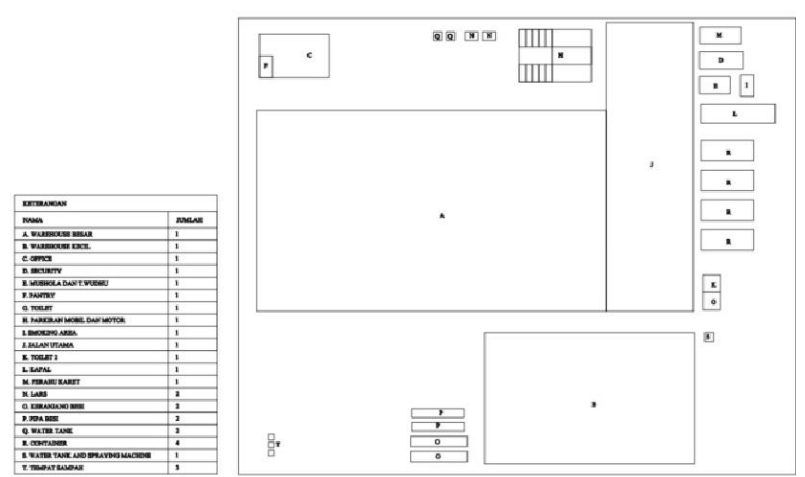

Gambar 7. Tamplate

Pada Tamplate dihasilkan gambaran dari semua perhitungan corelap berdasarkan nilai hasil akhirnya. Setelah semua iterasi selesai,maka didapatkan hasil tata letak dengan posisi departemen yang berdekatan sesuai hubungan kedekatan yaitu ARC. Menghasilkan jarak antara departemen rata-rata 2 meter dan arak ke jalan utama antara 1 meter sampai 20 meter. area kosong tersisa yaitu seluas 800 meter
3. Simulasi Software Promodel

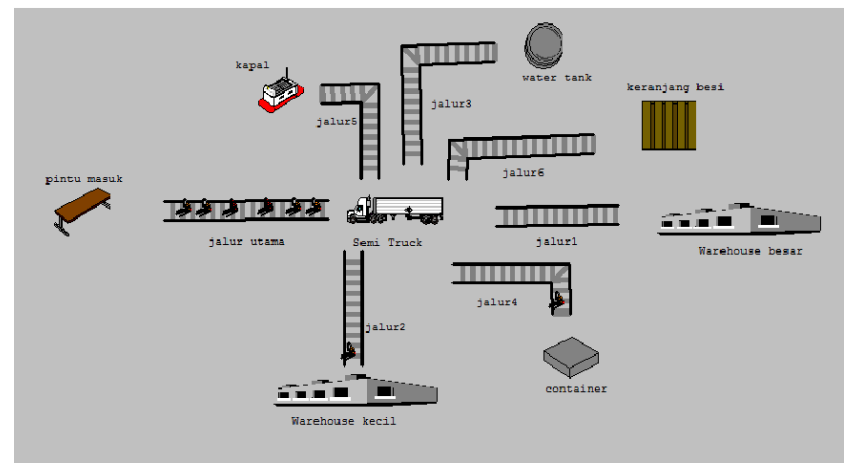

Gambar 8. Simulasi Promodel

Pada simulasi promodel didapatkan hasil simulasi dengan gambaran pergerakan material handling seperti gambar diatas. Semua barang menuju kepada jalan utama yang diangkut dengan forklift kepada truk.Dari hasil perhitungan simulasi menggunakan software promodel dapat dilihat peningkatan utilization. Pada pintu masuk tata letak awal menghasilkan utilization sebesar 93,77\% kemudian pada metode konvensional meningkat menjadi $94,18 \%$ dan pada metode corelap juga meningkat menjadi $94,18 \%$.

\section{SIMPULAN}

Tata letak usulan menunjukan beberapa peru bahan penempatan lokasi dari pada tata letak sebelumnya dan memberikan beberapa dampak. Diantaranya jarak antara pipa besi dengan keranjang besi yang yang sebelumnya berjarak 53 meter, pada tata letak usulan berjarak hanya 1 meter. Jarak antara 4 container yang sebelumnya memiliki jarak 10 meter, pada tata letak usulan hanya berjarak 1 meter.

Penataan lokasi warehouse menjadi lebih rapih berdasarkan hubungan kedekatan, area kosong sudah berkurang dan peralatan menjadi lebih dekat penempatannya dengan rata-rata kedekatan jaraknya 1 meter. Sehingga usulan atas perbaikan tata letak tersebut dirasa sangat bermanfaat diterapkan pada warehouse perusahaan, hal ini merupakan pembelajaran untuk perusahaan untuk meningkatkan kapasitas yang lebih optimal.

Perlu adanya perbaikan berupa evaluasi dari sistem yang ada kemudian melakukan perbaikan terus menerus agar warehouse dapat terus memberikan kontribusi yang baik untuk perusahaan

\section{UCAPAN TERIMA KASIH}

Ucapan terima kasih terutama ditujukan kepada Tuhan YME karena masih diberi umur dan kesehatan untuk dapat menyelesaikan laporan ini. Ucapan 
terima kasih juga disampaikan kepada orang tua, Bapak dan Ibu dosen pembimbing serta seluruh pihak yang membantu pelaksanaan penelitian.

\section{REFERENSI}

[1] H. Purnomo, Pengantar Teknik Industri. Yogyakarta: Graha Ilmu.2003.

[2] K. Lockyer, A. Muhlemann, \& J. Oakland, Production and Operations Management. Jakarta: Gramedia. 1990.

[3] Q, A. Dwianto, S. Susanty, \& L. Fitria, Usulan Rancangan Tata Letak Fasilitas Dengan
Menggunakan Metode Computerized Relationship Layout Planning (Corelap) Di Perusahaan Konveksi. Jurnal Online Institut Teknologi Nasional. 04 (01) hlm 87-97. 2016.

[4] A. Alfian, Sistem Antrian Kantor Pajak dengan Model Simulasi (studi kasus Jalan Kapten A.Rivai). jurnal Seminar Nasional Riset dan Teknologi 2018 (RITREKTRA 2018). Hlm. TI-1 - TI-13. 2018.

[5] D. Indrajaya \& R. Cornellia. Analisis model antrian loket transaksi pada pt. Pos Indonesia (persero) kantor cabang sawangan dengan menggunakan software promodel. Jurnal String. 3 (2) hlm 170-175. 2018. 